\title{
المؤثرات التخطيطية لتحديد الاحتياجات السكنية في المدن العراقية ناحية النصر والسلام كحالة تطبيقية
}

\section{Planning Indicators for Housing Needs in Iraqi Cities}

\section{Alnaser wa Alsalam case study}

م. د سهاد كاظم عبد الموسوي

جامعة الكوفة / كلية التخطيط العمراني

مستخلص البحث: - 2

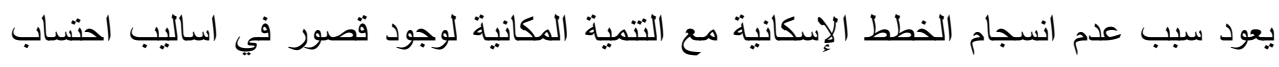

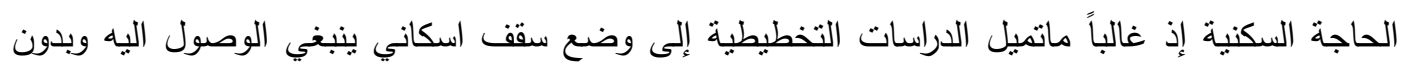

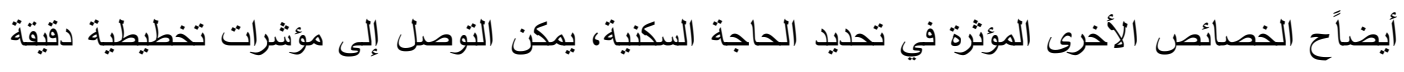
وخطة اسكانية لتحديد الاحتياجات الإسكانية ليس فقط من خلال تقدير العدد المطلوب للوحدات السكنية

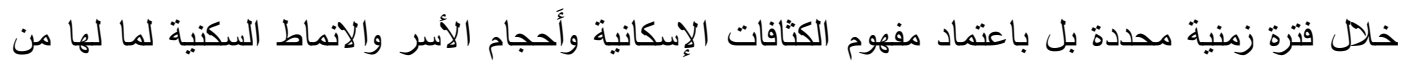
تاثير على تحديد ملامح النطوير الإسكاني للمناطق الحضرية، تم تطبيق فرضية البحث على مدينة نموذجية تابعة لمحافظة بغداد (ناحية النصر والسلام) وتم حساب المؤشرات التخطيطية للاسكان فيها ولغاية سنة هدف محددة وأوضحت النتائج انه يمكن اعتماد تللك المؤشرات كوسيلة للتوصل إلى الثى الخطط الإنسكانية الملائمة للمنطقة وحسب خصائصها المكانية والسكانية. 
Determining housing needs by summarizing the total housing units is not a precise indicator, which should be supported by other effective indicators such as housing densities, household size and housing type (single houses or apartment), these indicators affect housing projects for urban areas, the research hypothesis had been applied for a typical study area in Baghdad region (Alnaser wa Alsalam), housing forecast had been detected for a goal year and results showed that applying these indicators is preferable to outline the housing master plan for the urban area within its spatial and population characteristics.

\section{مشكلة البحث:}

تعاني غالبية المدن العراقية من مشكلة اسكانية واسعة، وغالبا ما تركز اغلب تقديرات الحاجة

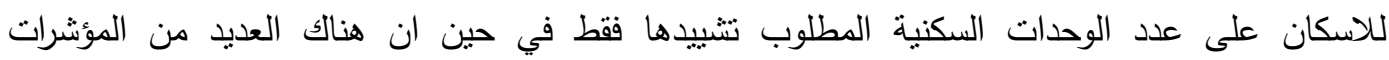
التخطيطية الإسكانية الأخرى التي ينبغي الاخذ بها وليس فقط عدد الوحدات السكنية.

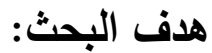

تقدير الاحتياجات التخطيطية للاسكان بناء على مفاهيم عدد الوحدات السكنية والكثافة الإسكانية وانماط الإسكان المطلوبة وتقديرات مساحات الأرض المطلوبة ولسنة هدف محددة لحالة تطبيقية نموذجية

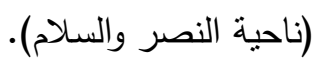

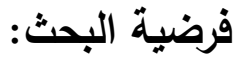

عدم كفاية تحديد الحاجة السكنية لأي منطقة حضرية من خلال تحديد عدد الوحدات السكنية

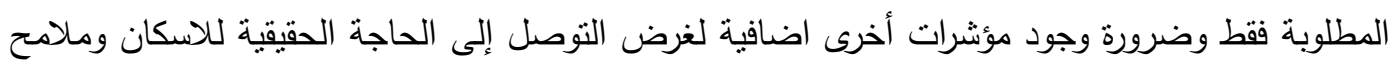
الخطة الإسكانية الملائكة لأي منطقة حضرية. 


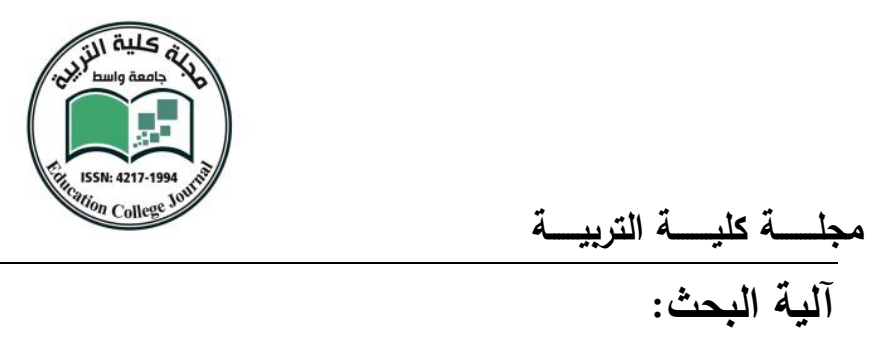

تحليل بيانات واقع الحال المتوفرة عن ناحية النصر والسلام من حيث عدد السكان والوحدات السكنية ومساحات الأراضي المخصصة للسكن لغرض التوصل إلى المعايير التخطيطية الإسكانية الملائمة للمدينة.

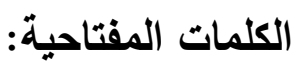

خطة اسكانية، المؤشرات الإسكانية، الكثافة الإسكانية، أَحجام الأسر، عدد أَفراد الأسرة، انماط السكن،

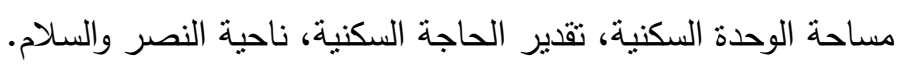


تميل غالبية تخمينات الحاجة السكنية إلى ذكر عدد الوحدات السكنية فقط لغرض اعطاء صورة عامة عن الوضع الإسكاني لمنطقة معينة، قد نساعد مثل هذه التخمينات على تقدير الكلفة المطلوبة

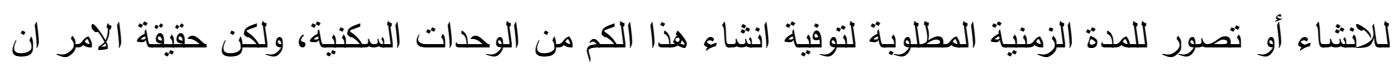

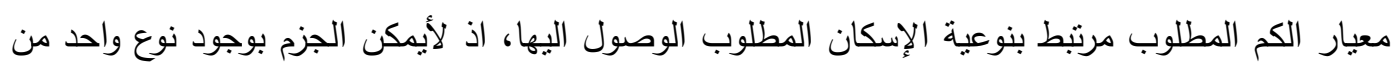

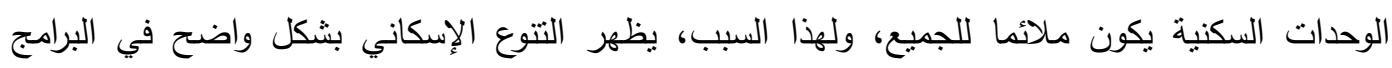

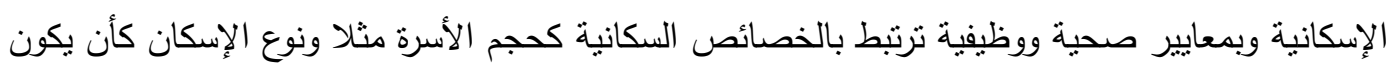
افقيا أو عموديا.

لاتظطرق تخمينات الحاجة السكنية بشكلها البسيط إلى مساحات الأراضي المطلوب توفيرها اذ ان

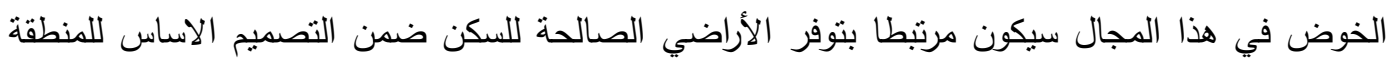

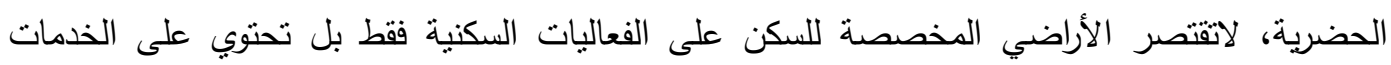
الاجتماعية للساكنين منل الفعاليات التعليمية والصحية وغيرها والتي تحتاجها اي منطقة سكنية.

تكون تخمينات الحاجة السكنية اكثر دقة إذا ما ارتبطت بتحديد مؤشرات تخطيطية تعطي صورة أوضح عن الخصائص السكانية وكذلك عن الميول والرغبات العامة حول شكل الإسكان المقبول اجتماعيا،

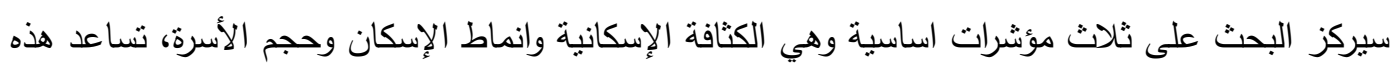

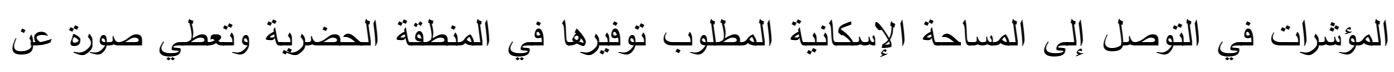
حجم تخصيصات الأراضي المطلوبة لغرض نوفير السكن. 
العــــــدد الثالث والعشرون

مجلــــة كليــــة التربيـــة

المبحث الأول الاطار النظري للمؤشرات الموئثرة في تحديد الحاجة السكنية

\section{1 إلمؤشرات التخطيطية المؤثرة في تحديد الحاجة السكنية}

توجد مجموعة من العوامل المؤثرة في تحديد الحاجة السكنية لأي منطقة حضرية ويمكن نوصيفها

\section{1-1- الكثافة الإسكانية}

وهي المعيار الاكثز استخداما في تحديد حجم الإسكان ضمن مساحة معينة، تقاس الكثافة الإسكانية بعدد الاشخاص لكل هكتار أو عدد الأسر لكل هكتار وتتقسم لنوعين، كثافة اجمالية حيث يتم احتساب اعداد الاشخاص أو الأسر لكامل مساحة المنطقة (بكافة استعمالات الأرض) أو كثافة صافية

حيث يتم احتساب الاعداد لاستعمالات الأرض السكنية فقط ('). حدد مخطط الإسكان العام بالعراق ستة أصناف من الكثافة الإسكانية لوحدة الجيرة Neighborhood بالعلاقة مع نمط الإسكان (افقي أو عمودي) وكما موضح في جدول (1) من (1).

\begin{tabular}{|c|c|c|}
\hline \multicolumn{3}{|c|}{ جدول (') } \\
\hline \multicolumn{3}{|c|}{ الكثافات الإسكانية بالعلاقة مع شكل الوحدة السكنية حسب المخطط العام للاسكان } \\
\hline كثافة السكان (شخصا هكتار) & الكتافة الإنسكانية (وحدةا هكتار) & 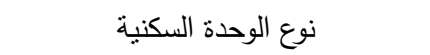 \\
\hline $1 r \cdot-\lambda$. & $r-1 r$ & مسنقلة Detached \\
\hline $17 .-11$. & $r v-11$ & $\begin{array}{c}\text { Semi تلاصقة من جهة واحدة } \\
\text { Detached }\end{array}$ \\
\hline$r 0 .-1 \leqslant$. & $\varepsilon r-r \varepsilon$ & متلاصقة Row Houses \\
\hline$r q .-1 v$. & $\{\Lambda-r \wedge$ & $\begin{array}{c}\text { دور ذوات باحة وسطية Courtyard } \\
\text { Atrium House }\end{array}$ \\
\hline$\varepsilon \ldots-r_{n}$ & ᄉ.- $\varepsilon$. & $\begin{array}{c}\text { المجمعات السكنية محدودة الارتفاع } \\
\text { Low Rise }\end{array}$ \\
\hline o...ro. & $14 \cdot-4$. & High Rise العمارات السكنية العالية \\
\hline
\end{tabular}


مجأ أنماط الإسكان

يعتد نمط الإسكان الملائم لأي منطقة حضرية على الكتافات الإنكانية فالكثافات القليلة (لغاية

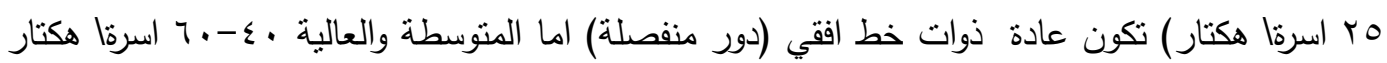

$$
\text { فنكون ذوات نمط عمودي (عمارات) (r). }
$$

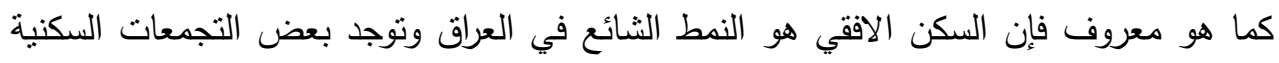

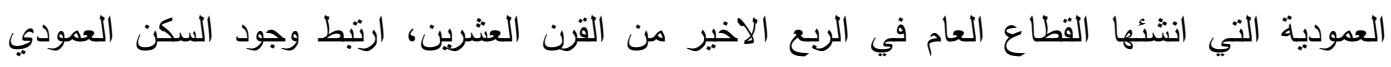

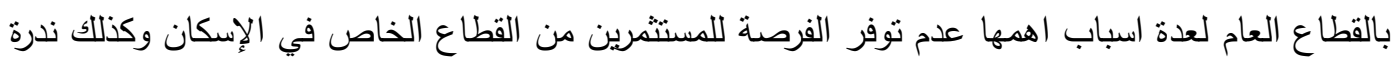

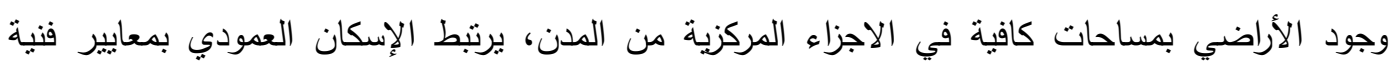
محددة لغرض تحقيق مستوى سكن معين يراعي الجوانب الصحية والبيئية والاجتماعية.

تكون الرغبة في اعتماد نمط سكني معين (افقي أو عمودي) لأي منطقة حضرية نابعة من العديد

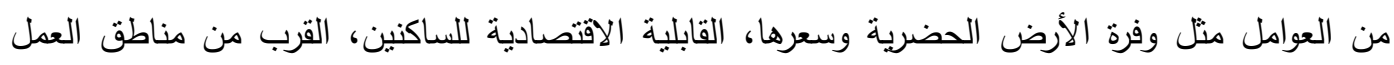

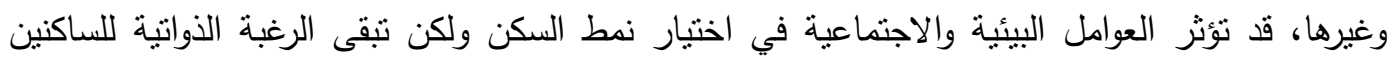
وظروفهم الخاصة هي العامل الاكثر تاثيرا في ذلك (").

تختلف روئة المجتمعات الحضرية لنمط الإسكان في دول العالم، تميل الستراتيجيات التخطيطية

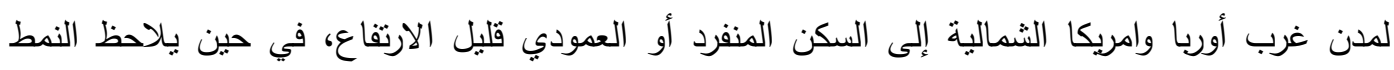

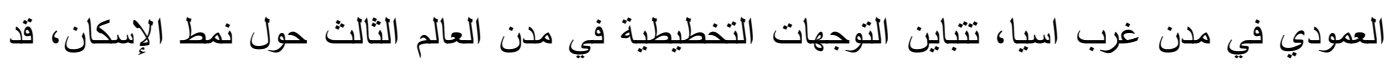

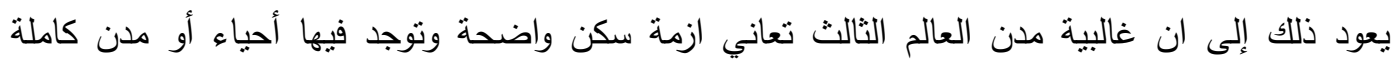
لأيتوفر فيها للساكنين مقومات الكفاية الحياتية(i).

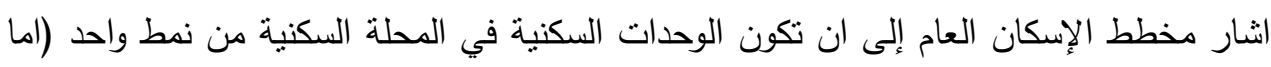
افقي أو عمودي)، اعتمادا على الكثافة السكانية المطلوب تحقيقها في المنطقة. 
وفيما يتعلق بالسكن العمودي فقد حدد مخطط الإسكان العام نوعين منه، الأول شقق سكنية ذوات ارتفاع واطئ (لأيتجأوز اربعة طوابق) والثاني شقق سكنية في عمارات عالية (وهذه يقتصر نواجدها في ني

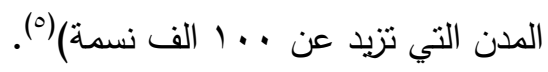

\section{r-1}

يعتمد نمط الإسكان أيضاً على حجوم الأسر، تنيل أغلب الأساليب التخطيطية إلى توفير الدور

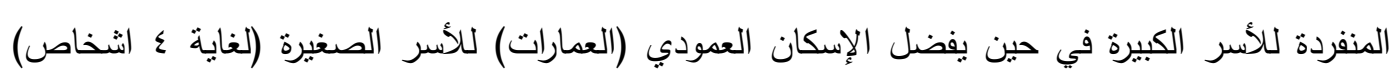

تثير المصادر إلى وجود اربعة حجوم للأسرة في العراق وكما في جدول (r).

\begin{tabular}{|c|c|c|}
\hline \multicolumn{3}{|c|}{ جدول (ץ) } \\
\hline \multicolumn{3}{|c|}{ حجوم الأسر في العراق لغاية عام .... } \\
\hline النسبة إلى مجموع الأسر & عدد أَفراد الأسرة & حجم الأسرة \\
\hline \%rr & $r-1$ & صغيرة \\
\hline$\%$ \% & $\uparrow-\varepsilon$ & متوسطة \\
\hline$\% r v$ & $q-\gamma$ & كبيرة \\
\hline$\% \wedge$ & . ا فاكثر & كبيرة جدا \\
\hline \multicolumn{3}{|c|}{ 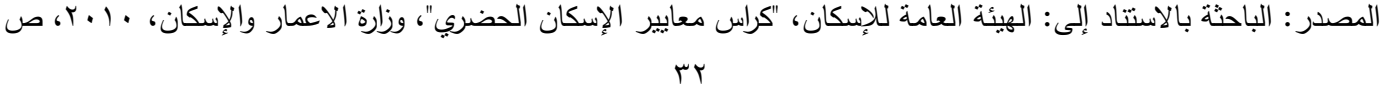 } \\
\hline
\end{tabular}

وكما يتضح في الجدول (Y) فانه توجد ؛ حجوم اساسية للأسر حيث تتكل الأسر المتوسطة الحجم

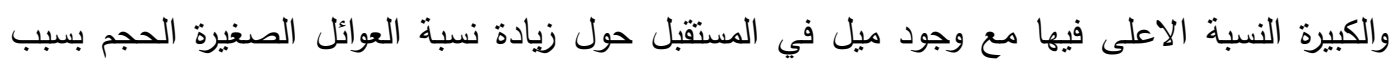

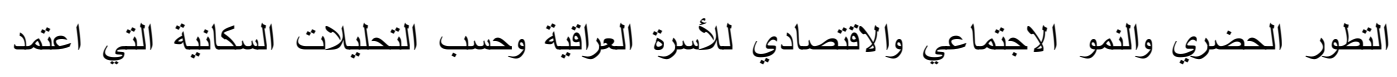
عليها مخطط الإسكان العام).

لقد انعكست فكرة حجم الأسرة على مساحة الوحدة السكنية، اثنار مخطط الإسكان العام لمساحة

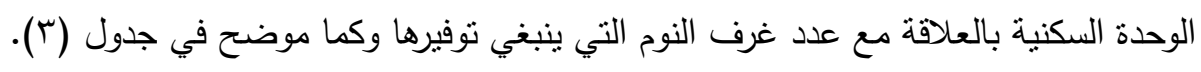


العـــــــد الثالث وإلعشرون

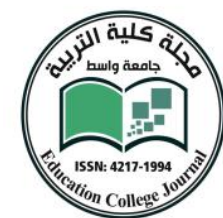

\section{مجلــــة كليـــة التربيـــة}

\section{جدول (r)}

تصنيف مساحة الوحدة السكنية بالعلاقة مع حجم الأسرة

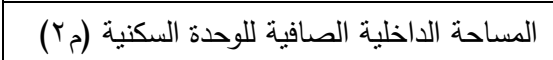

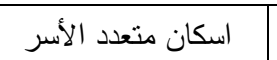

\begin{tabular}{|c|c|c|c|c|}
\hline اسكان متعدد الأسر & اسكان منفرد (دور) & عدد غرف النوم & حجم الوحدة السكنية & حجم الأسرة \\
\hline$T r-O V$ & - & 1 & S1 & \multirow{2}{*}{ صغيرة } \\
\hline $10-7 q$ & $11-V_{0}$ & $r$ & $\mathrm{~S} 2$ & \\
\hline
\end{tabular}

\begin{tabular}{|c|c|c|c|c|}
\hline & & & & \multirow{2}{*}{ صغيرة } \\
\hline Vo-79 & N1-V0 & r & $\mathrm{S} 2$ & \\
\hline $99-94$ & $1.0-99$ & r & M1 & \multirow{2}{*}{ متوسطة } \\
\hline $11 \leq-1 \cdot 1$ & $\mid r \cdot-11 \leq$ & $r$ & M2 & \\
\hline $1 \leq \vee-1 \Gamma \wedge$ & $10 V-1 \leqslant V$ & $\varepsilon$ & L & كبيرة \\
\hline- & $1 \wedge \cdot-171$ & 0 & E1 & \multirow{2}{*}{ كبيرة جدا } \\
\hline- & או1ו-190 & ד فاكثر & E2 & \\
\hline
\end{tabular}




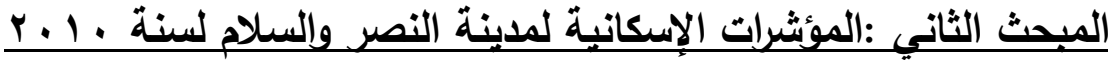

تقع ناحية النصر والسلام ضمن قضاء ابي غربب التابع لمحافظة بغداد وتعتبر نقطة ربط اساسية لمدينة بغداد مع المناطق الغربية للعراق، (مخطط - 1-)، يسكن في المدينة حوالي . .... . . . نسمة

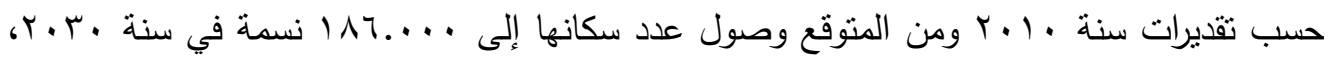

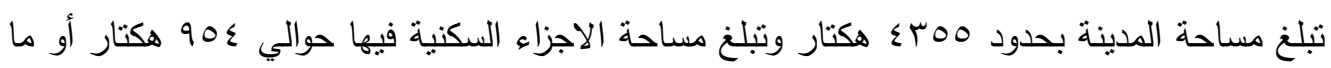
يعادل r r\% من مساحة المدينة(^)، تعد ناحية النصر والسلام نموذجا للمدن الصغيرة منتوعة الاقتصاد المحيطة بالعاصمة بغداد، تعاني المدينة من ازمة سكن ونقص في عدد الوحدات السكنية المتوفرة وحاجة إلى اعادة التأهيل شكل (1) ، نتوافر في ناحية النصر والسلام العديد من بدائل التوسع لتوفير الحاجة السكنية للمدينة وقد تم اختيارها كحالة تطبيقية لأمكانية توفير العديد من العوامل التخطبطية الإسكانية منل الكثافة المناسبة تخطيطياً وصحياً وانماط اسكان جديدة عند اعداد مخططات التوسع

(9) (9) - (9) 


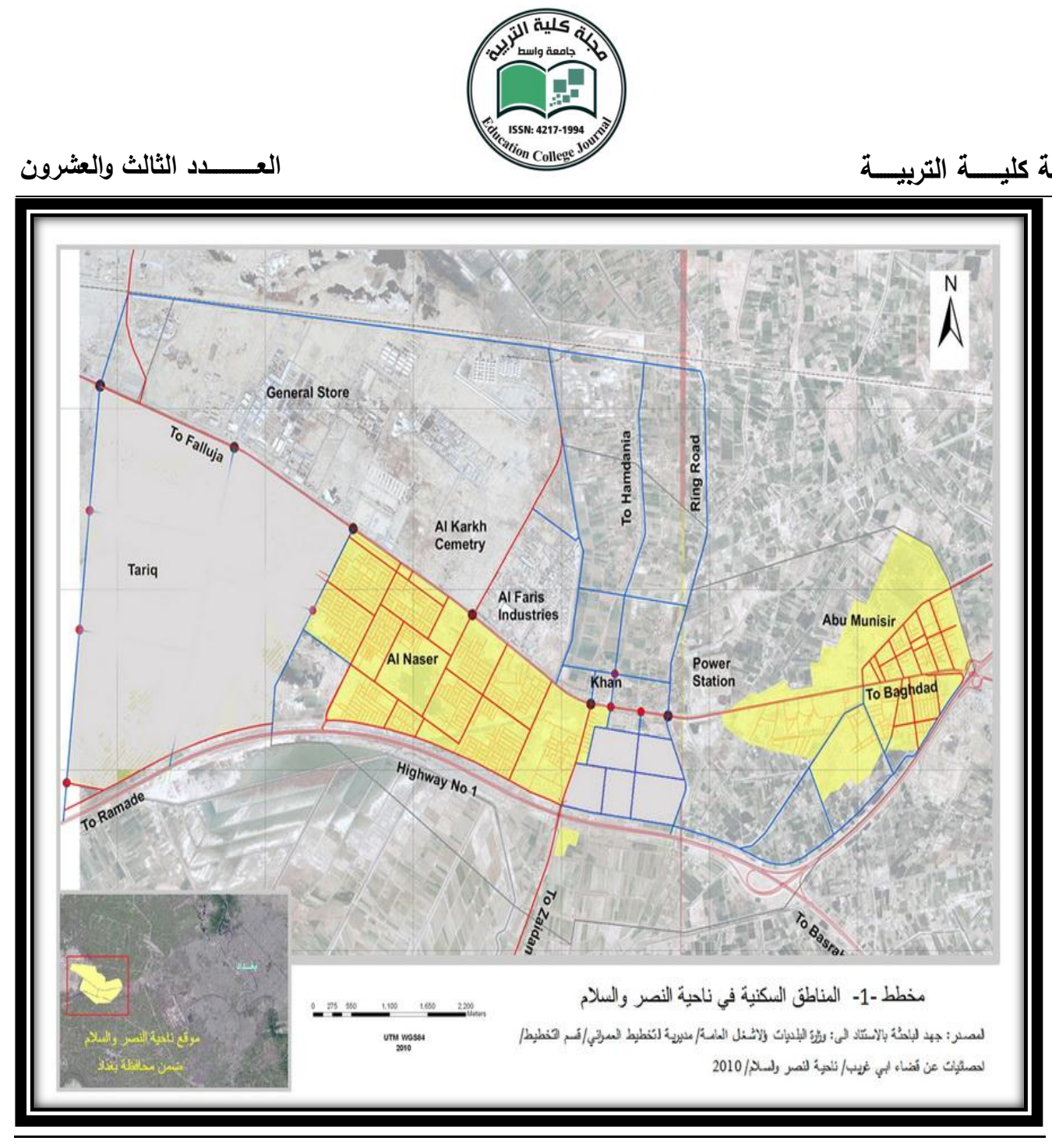

\section{r- - الكثافة الإسكانية في مدينة النصر والسلام}

وفقا للبيانات المتوفرة ، فقد امكن التوصل إلى تحديد بعض الكثافات الإسكانية لمدينة النصر والسلام، وكما

موضح في الجدول (1). 


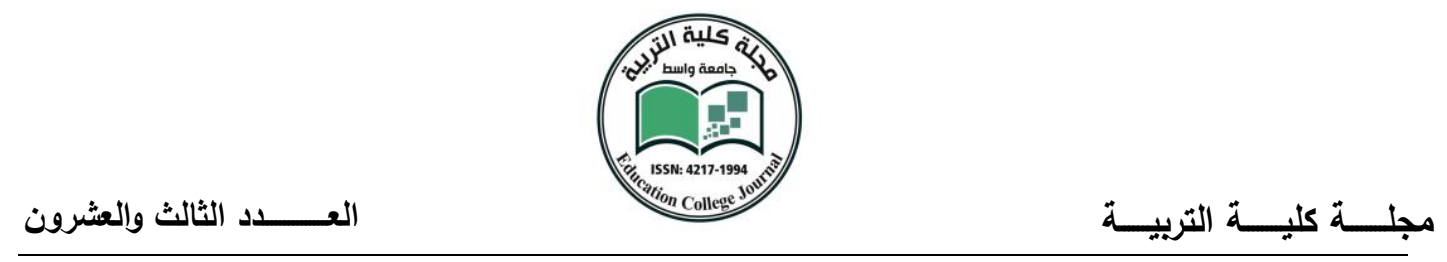

(1) (1) (1)

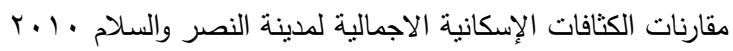

\begin{tabular}{|c|c|c|c|}
\hline مخطط الإسكان العام (وزارة & حسب نظرية وحدة الجيرة & النصر والسلام & الكثافة الإسكانية \\
\hline$r \varepsilon$ & ro & ir & عدد الوحدات السكنيةاهكتار \\
\hline$r \varepsilon$ & ro & $r \varepsilon$ & عدد الأسراهكتار \\
\hline 10. & VA & 1.1 & عدد الساكنين|هكتار \\
\hline
\end{tabular}

المصدر : جهد الباحثة بالاستتاد إلى: وزارة البلديات والاشغال العامة/ مديرية التخطيط العمراني/ قسم التخطيط/ احصائيات عن

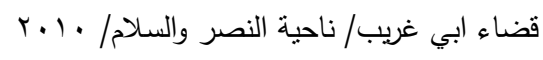

يتضح من الجدول (1) أعلاه ان هناك كثافة منخفضة للوحدات السكنية في المدينة مقارنة بالمعايير المشابهة، وحقيقة هذا الامر ان هناك العديد من الأراضي السكنية الفارغة التي لم يتم تشبيد اي دور عليها لحد توفر البيانات، ولأيثنير كما يظهر للوهلة الأولى ان مساحات الأراضي المخصصة للوحدات السكنية كبيرة مما انعكس على كثافتها المنخفضة.

ويثبت الامر أعلاه ارتفاع كثافة الأسر في المدينة والتي تعادل ضعفي كثافة الوحدات السكنية فيها، أو ببساطة ان كل اسرتين تسكن وحدة سكنية واحدة.

وفقا لهذه الملاحظات فانه يمكن الاستدلال مبدئيا على ان المساحة المخصصة للسكن هي كافية للسكان حاليا، ولكن المشكلة تكمن في عدم تشبيد وحدات سكنية في المدينة، مما انعكس على هذه الحالة، وبالنظر إلى ان غالبية الأراضي السكنية مملوكة لمواطنين من المدينة، فان انثاء الدور عليها سيخضع لرغبتهم وامكانياتهم المادية، مما يستدعي ايجاد اساليب ملائمة فنيا لحل هذه المشكلة. 
يمكن الاستدلال أيضاً على كفاية مساحات الأراضي السكنية في المدينة من خلال كثافة الاشخاص في الهكتار الواحد، والتي تعد وفق المعايير متوسطة نسبيا، وبحدود ... شخص لكل هكتار، مقارنة بالمعايير المشابهة.

ترى الباحثة ان مستويات الكثافة في مدينة النصر والسلام مقبولة تخطيطيا للاجزاء المشيدة حاليا في

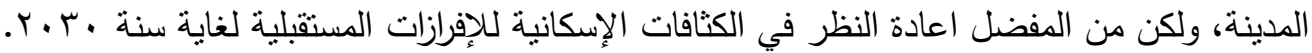

\section{r-r}

وفقا للبيانات المتوافرة عن المدينة سنة • ب.r، الوحدات السكنية إلى الاضافة والترميم

$$
\text { والخدمات، وكما موضح في الجدول (r). }
$$

بالنظر لان غالبية الوحدات السكنية في المدينة مملوكة للمواطنين، فمن المؤكد ان الحاجات

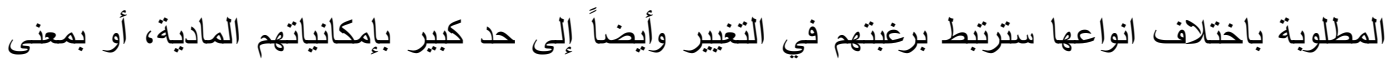
اخر انه من الصعب احداث تغيير في واقع حال الوحدات السكنية من خلال السكان مالم برتبط ذللك بتحسين الوضع المادي لهم من خلال توفير فرص العمل في المدينة.

ترى الباحثة انه من الممكن ان تسهم الادارات المختصة في عملية اعادة التأهيل وذلك من خلال تحسين الخدمات الفنية والاجتماعية والمناطق الخضراء في المناطق السكنية، لا تؤيد الباحثة وجود حاجة أنة إلى ازالة أو اعادة تخطيط المناطق السكنية الموجودة حاليا بشكل جذري، ولكن بنبغي التركيز في تحسين

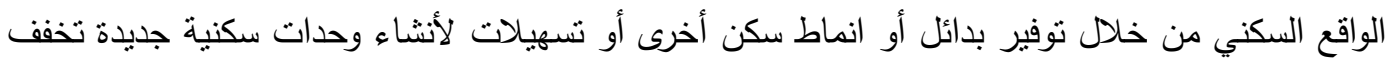

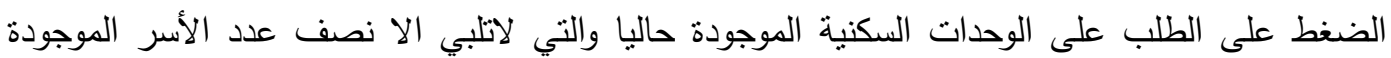
حاليا في المدينة.

ينبغي على الادارات المختصة اعداد برنامج تاهيل للمناطق السكنية الموجودة حاليا ضمن الحدود البلدية للمدينة وبمدد محددة لغرض الوصول إلى مستوى مناسب للمناطق السكنية ويلبي حاجة الساكنين

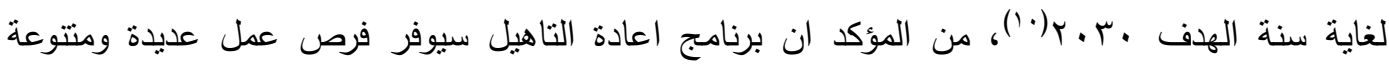




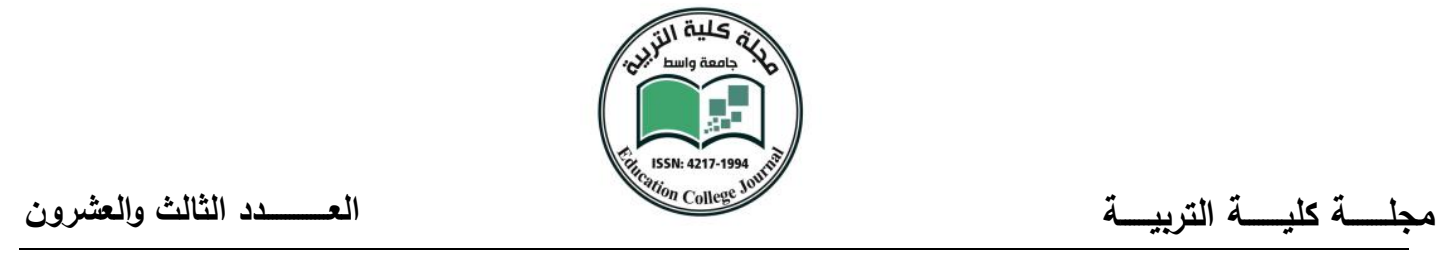

بامكان السكان الاستفادة منها في تحسين وضعهم المادي فضلاً عما بمكن ان بنتج في تغير في اسعار الأراضي في المناطق السكنية وارتفاع قيمتها بفعل إضافة الخدمات اليها.

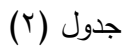

حاجة الوحدات السكنية إلى الاضافة والترميم والخدمات في مدينة النصر والسلام

\begin{tabular}{|c|c|c|c|}
\hline عدد الوحدات السكنية (\%) من اجمالي & طبيعة الاحتياج & عدد الوحدات السكنية (\%) من اجمالي & طبيعة الاحتياج \\
\hline$\varepsilon$. & الحاجة للاضافة & vo & الصيانة العامة \\
\hline$\leqslant 1$ & اضافة غرف نوم & 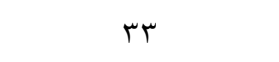 & صيانة خدمات تحتية \\
\hline r & اضافة طابق & iv & صيانة الهيكل الانثائي \\
\hline \multirow[t]{2}{*}{ זr } & توسيع غرفة المعيشة & rt & الانهاءات \\
\hline & & $r V$ & الواجهات \\
\hline
\end{tabular}

المصدر : وزارة البلديات والاشغال العامة/ المديرية العامة للتخطيط العمراني/ قسم التخطيط/ احصائيات غير منشورة عن قضاء

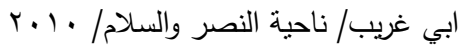

\section{1- الإسكان في مدينة النصر والسلام لغاية سنة الهرف .r.r}

\section{ب- - الكثافة الملائمة لمدينة النصر والسلام}

يمكن توفير العديد من الكثافات الإسكانية في مدينة النصر والسلام وذلك من خلال توفير انماط سكن وخيارات تلبي جميع احتياجات سكان المدينة على اختلاف حجوم الأسر ووضعهم الاقتصادي.

ترى الباحثة ضرورة توفير كثافات بشكل أعلى من واقع الحال الموجود الذي يقدر بحدود ؟Y أسرة الهكتار،

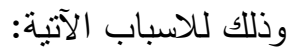


ا- الدخل المحدود لاسر مدينة النصر والسلام مما يعني توفير فرص للسكن ضمن قابلياتهم المادية وبمساحات تلبي احتياجهم.

ץ- حاجة المدينة لأنواع الخدمات كافة وما يرتبط بها من كلف انثاء لخدمة السكان مما يجعل الكلفة الاقتصادية لها اقل بزيادة عدد السكان الذين تخدمهم.

r- تقليل المساحة المطلوبة للتوسع الحضري قدر الامكان وعدم التبذير بالأرض الحضرية أو تقليل

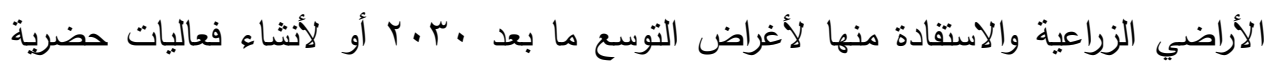
أخرى.

ع- وجوب تهيئة المدينة لاحتمالات النمو غير المتوقعة في المستقبل خصوصا ان المدينة تحتوي

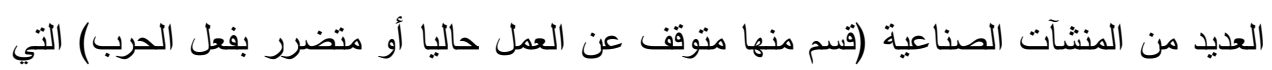
يمكن ان تجنذب العديد من الأسر من خارج المدينة.

ه- ضرورة مراعاة الجانب البيئي والمناخي في المدينة وذلك من خلال تقليل مساحات الفضاءات المفتوحة وشبكات الثوارع التي من المعروف علميا انها تسهم في ارتفاع درجات الحرارة.

ان الاسباب أعلاه لا تعني ان الباحثة تتظر إلى مدينة النصر والسلام على انها مدينة لسكان من

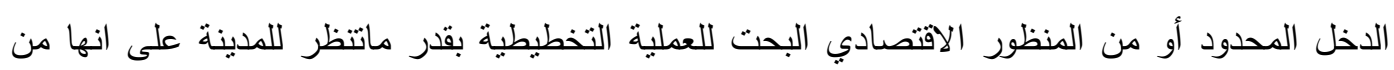

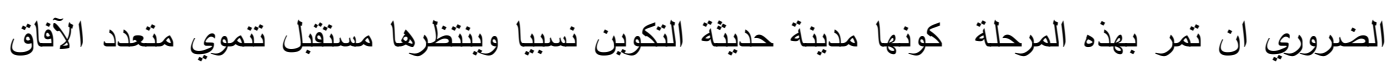
يحتاج إلى قواعد منطقية للتخطيط اكثر من استتساخ لتجارب أو لسياسات اسكانية مشابهة.

يمكن ايجاز الكثافات التي تقترحها الباحثة لمدينة النصر والسلام نحو ما هو موضح في الجدول (ب). 


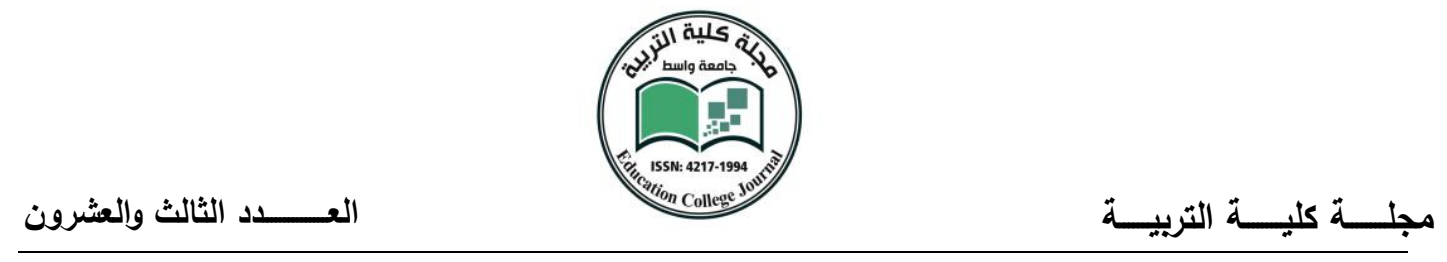

جدول (r)

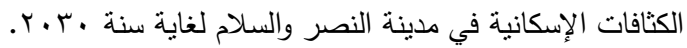

\begin{tabular}{|c|c|c|c|c|c|c|c|}
\hline \multirow{3}{*}{ معدل عدد أَفراد } & \multicolumn{6}{|c|}{ الكثافة الإسكانية المقترحة } & \multirow{3}{*}{ انواع الوحدات السكنية } \\
\hline & \multicolumn{3}{|c|}{ شخص|هكتار } & \multicolumn{3}{|c|}{ وحدة سكنية|هكتار } & \\
\hline & 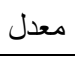 & 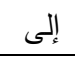 & 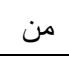 & معدل & 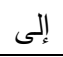 & 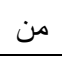 & \\
\hline 7 & $1 \leq$. & 17. & ir. & tr & ry & r. & دور سكن \\
\hline 0 & 17. & $1 \wedge$ & $1 \leq$ & r & 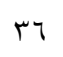 & צ & دور سكن \\
\hline$\varepsilon$ & rl. & . ז & 17. & or & Tr & $\varepsilon r$ & عمارات سكنية \\
\hline
\end{tabular}

المصدر: جهر الباحثة بالاعتماد على وزارة البلديات والاشغال العامة/ المديرية العامة للتخطيط العمراني/ قسم التخطبط/

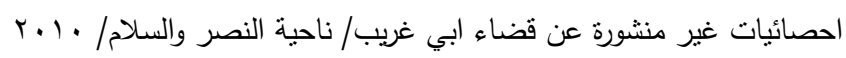

وكما يتضح من الجدول (r)، فقد اقترحت الباحثة ايجاد ثلاث مسنويات للكثافات على مسنوى الوحدات السكنية والاشخاص، وبالعلاقة مع عدد أَفراد الأسرة، وعلى اساس ان زيادة الكثافة سواء على مستوى الوحدات أو الاشخاص سيتتاسب عكسيا مع عدد أَفراد الأسرة، أو بمعنى اخر صياغة مساحات الأراضي بالثكل الذي يلبي عدد أَفراد الأسرة، فكلما تكون الأراضي اكبر فانها ستستوعب اسر اكبر، والعكس صحيح أيضاً، يمكن ملاحظة ان الباحثة قد خصصت العمارات السكنية للأسر الصغيرة أو حديثة التكوين بحيث تتلائم مع امكاناتها المادية. 


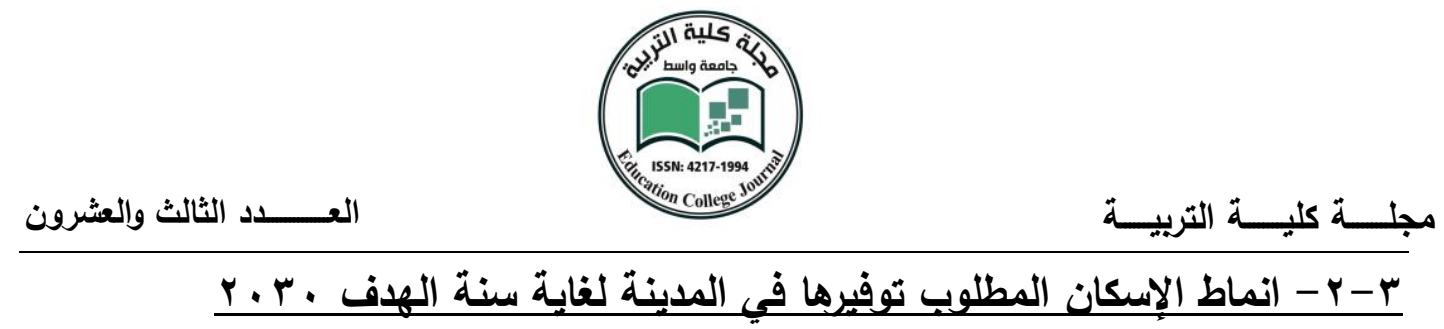

يشكل السكن المنفرد (الدور السكنية) السمة العظمى في مدينة النصر والسلام وبمساحات اراضي

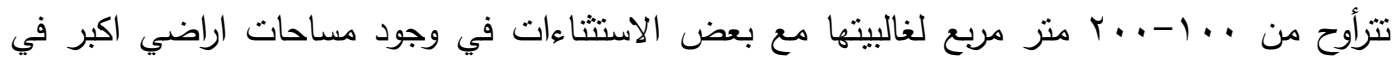

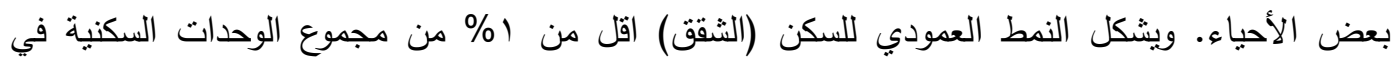

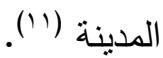

ترى الباحثة انه من الضروري زيادة نسبة إسهام السكن العمودي في توفير الوحدات السكنية في المدينة

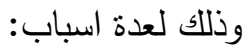

1- الميزة الاقتصادية للسكن العمودي من حيث توفير الخدمات والمساحات. ץ - خدمة عدد اكبر من السكان بنفس السساحة. r- قابلية نوفير المناطق الخضراء ضمن المجمعات السكنية بشكل اكبر • ع - تعزيز الروابط الاجتماعية بين السكان. ه- يمكن ان يوفر السكن العمودي وحدات سكنية للأسر قليلة الأفَراد أو الأسر حديثة التكوين. צ- تعزيز الثكل الحضري للددينة إذا يغلب على المدينة البناء الاققي وبطابق واحد.

تقترح الباحثة ادخال السكن العمودي كبديل لتوفير جزء من الوحدات السكنية المطلوبة لغاية سنة

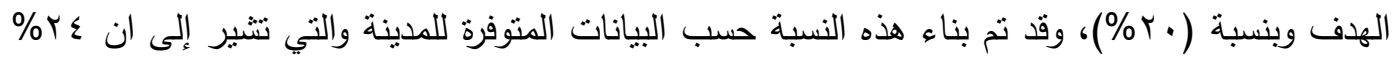

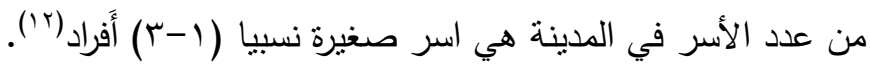

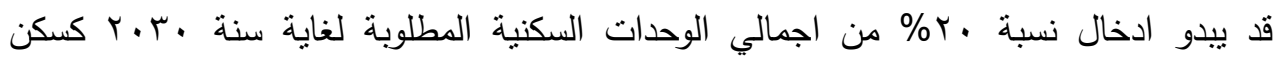
عمودي امرا غير اعتيادي للوهلة الأولى في مدينة النصر والسلام، ولكن الباحثة ترى انه البديل الوحيد الذي يضمن توفير وحدات سكنية باسعار مناسبة لسكان المدينة. 


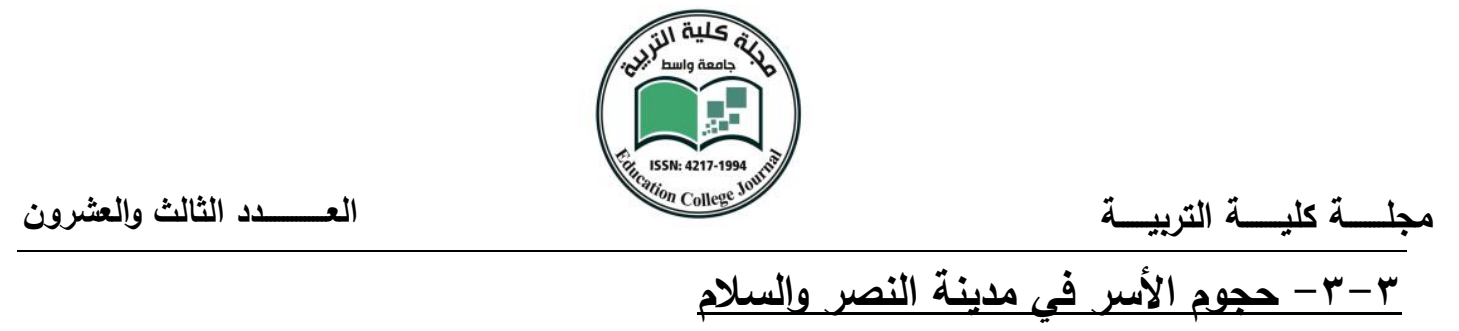

أوضحت البيانات المتوفرة عن المدينة ان هناك تباينا في حجوم الأسر في المدينة مما يستلزم

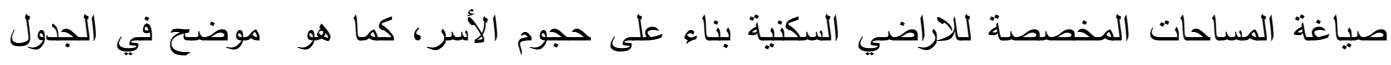

ترى الباحثة ان تحديد معيار المساحة لكل شخص كاساس لاحتساب مساحة الأرض اللازمة لتلبية

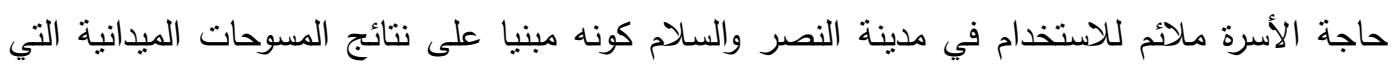

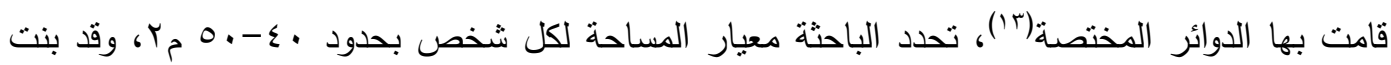

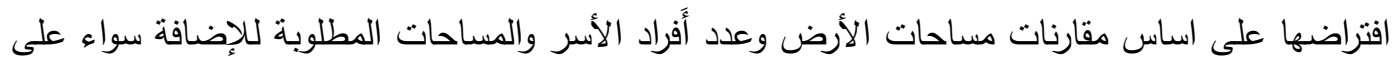
شكل غرف نوم أو معيشة أو طابق كامل وحسب ما ورد في البيانات المتوفرة عن المدينة، كما هو موضح في جدول (0). (0)

جدول (ई)

حجوم الأسر في مدينة النصر والسلام لسنة ـ ـ ـr.

\begin{tabular}{|c|c|}
\hline النسبة \% & عدد الأَفراد في الأسرة \\
\hline$r \varepsilon$ & ا \\
\hline v) & צ- ـ ـ أَفراد \\
\hline 0 & ||-0| فرد \\
\hline $1 .$. & المجموع \\
\hline
\end{tabular}

الصدر : وزارة البلديات والاشغال العامة/ الديرية العامة للتخطيط العمراني/ قسم التخطيط/ احصائيات غير منشورة عن قضاء

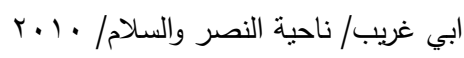




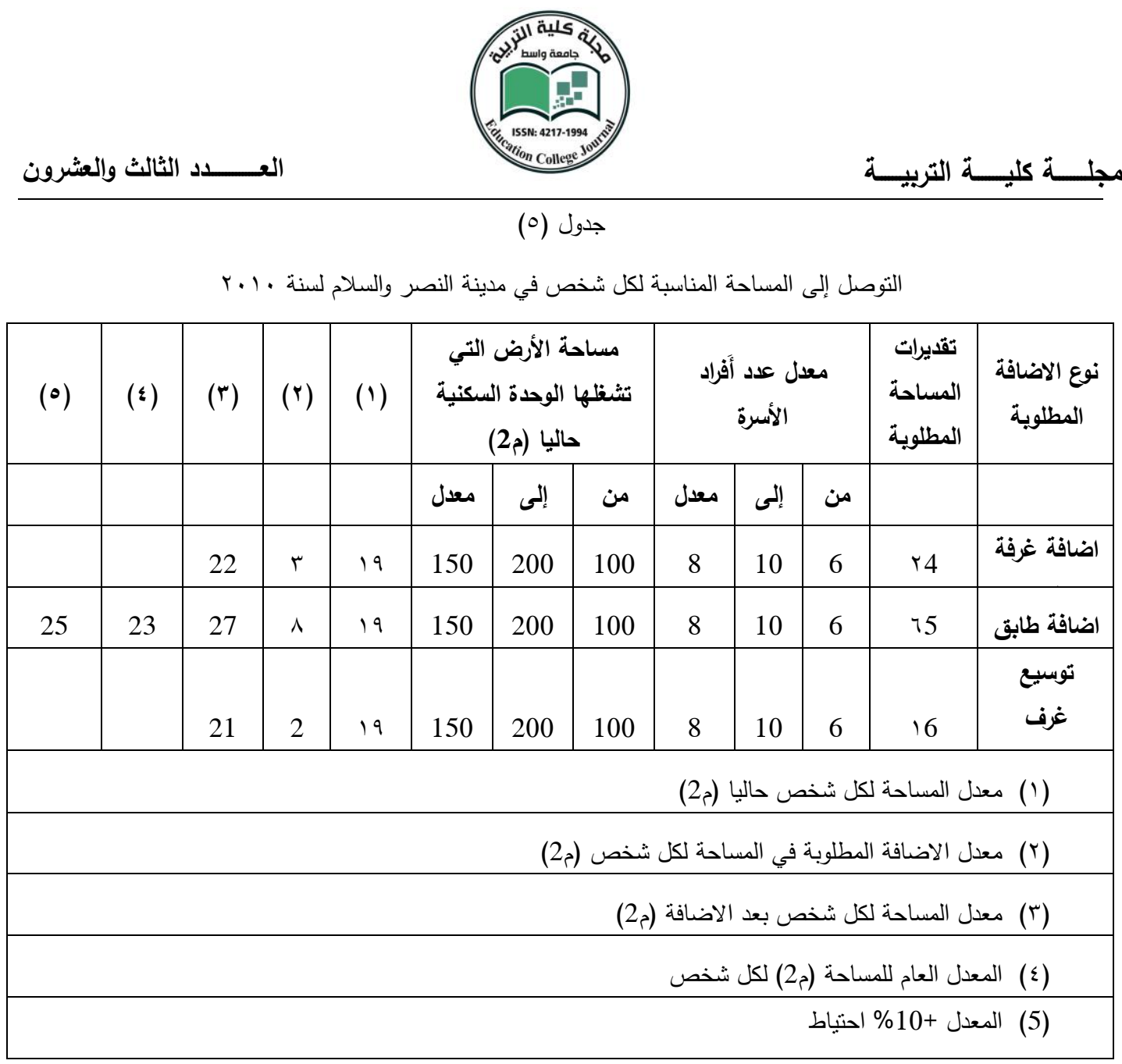

المصدر: جها الباحثة بالاعتماد على وزارة البلديات والاشغال العامة/ المديرية العامة للتخطيط العمراني/ قسم التخطبط/

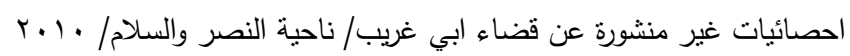

يتضح لنا من الجدول (0) ان المساحة المطلوبة للتوسع بحدود 0Y مY للبناء فقط، وقد ارتأت الباحثة اضافة مساحة أخرى لتغطية استخدامات الفضاءات الخارجية والحركة والحدائق ومواقف السيارات

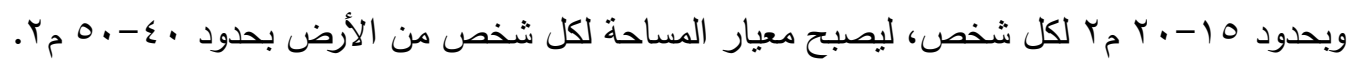


لاتتوقع الباحثة حصول تغير كبير في أَحجام الأسر في مدينة النصر والسلام لغاية سنة الهدف

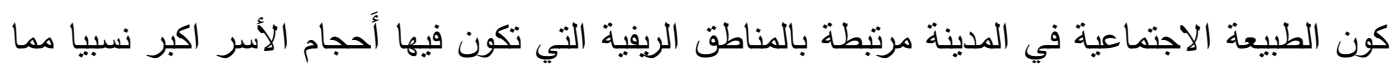
هو عليه الحال في المدينة. 
المبحث الثالث : تقدير الحاجة إلحى الوحدات السكنية في مدينة النصر والسلام لغاية سنة

الهُف . r.

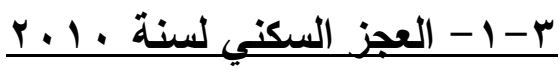

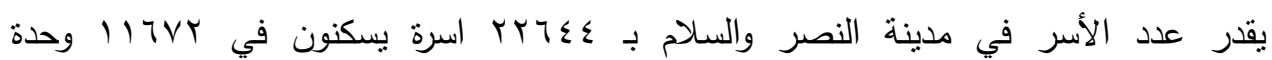

سكنية (؟).).

يمكن احتساب العجز السكني ببساطة من خلال طرح عدد المساكن من عدد الأسر والذي

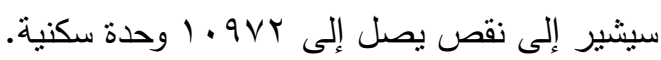

يشكل الرصيد السكني الموجود حاليا مانسبته فقط ror\% من حاجة الأسر في المدينة، وهو بلا شك يشير إلى حجم الجهد المطلوب في تثبيد الوحدات السكنية لغرض كفاية عدد السكان الموجود في المدينة.

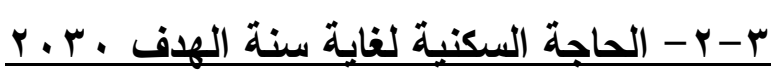

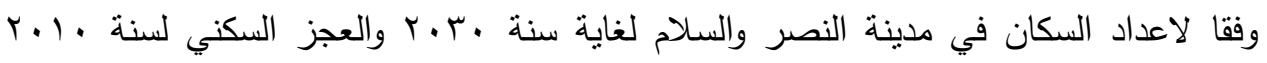
وباحتساب تخصيص وحدة سكنية لكل اسرة في مدينة النصر والسلام، يمكن تقدير عدد الوحدات السكنية المطلوبة في مدينة النصر والسلام وكما موضح في فئسة الجدول (؟).

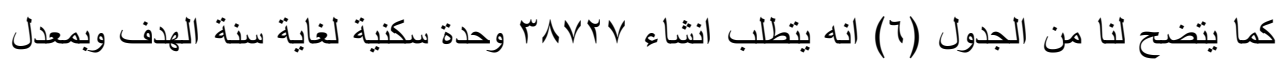
4وا 19 وحدة سكنية في السنة. لاشك في ان نتيبيد هذا العدد من الوحدات السكنية هو امر ليس بهذه

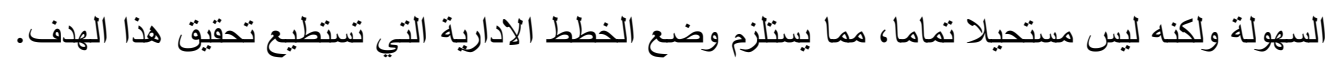




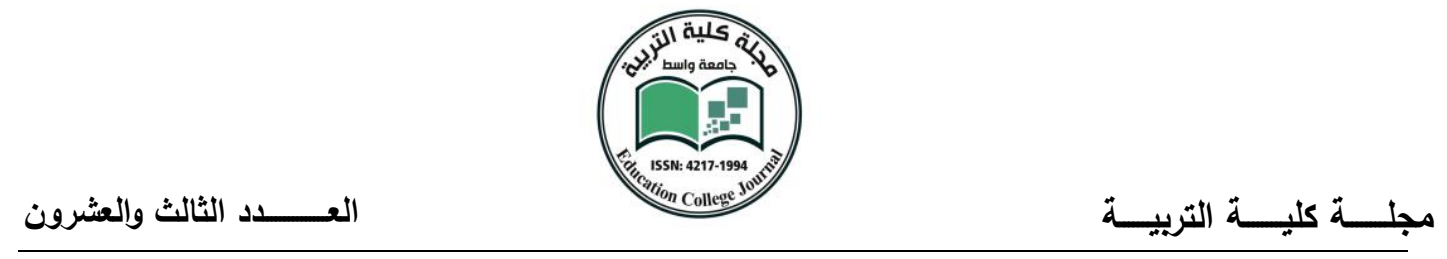

جدول (T)

عدد الوحدات السكنية المطلوبة في مدينة النصر والسلام لغاية سنة •r. ·.

\begin{tabular}{|c|c|c|c|}
\hline عدد الوحدات السكنية & عدد الأسر & عدد السكان & 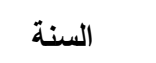 \\
\hline 10,972 & 22,644 & 96,147 & 201. \\
\hline 4,711 & 27,354 & 116,149 & 2015 \\
\hline 5,514 & 32,020 & 135,961 & 2020 \\
\hline 6,455 & 37,482 & 159,152 & 2025 \\
\hline 7,556 & 43,875 & 186,299 & 2030 \\
\hline 35,207 & \multicolumn{3}{|c|}{ 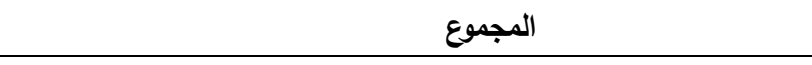 } \\
\hline 3,521 & \multicolumn{3}{|c|}{ اضافة 10\% لتغطية التهرؤ السكني } \\
\hline 38,727 & \multicolumn{3}{|c|}{ المجموع الاجمالي } \\
\hline 1,936 & \multicolumn{3}{|c|}{ معدل عدد الوحدات السكنية المطلوب انثائها خلال السنة } \\
\hline
\end{tabular}

المصدر: جهد الباحثة بالاعتماد على وزارة البلديات والاثغال العامة/ المديرية العامة للتخطيط العمراني/ قسم التخطيط/

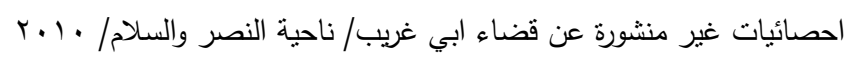

ـ - - تقبر المساحة اللازمة للاستخدام السكني في مدينة النصر والسلام

وفقا للمعيار الذي توصلت اليه الباحثة والمتضمن تخصيص • مم لكل ساكن من مساحة قطعة الأرض، فانه من الممكن احتساب المساحة المطلوبة للاغراض السكنية في مدينة النصر والسلام وفق

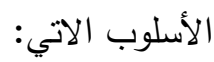

عدد الوحدات السكنية المطلوبة لسنة الهدف× معدل عدد أَفراد الأسرة×.0 مب+.ب\% حركة+ • ب \% احتياط ومراكز محلات. 
العــــــدد الثالث وإلعشرون

مجــــة كليـــة التربيـــة

يوضح الجدول (V) تقديرات مساحات الأراضي اللازمة المطلوب تخصيصها لاغراض الإنكان

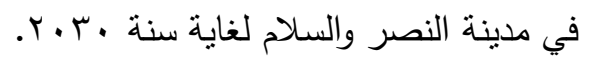

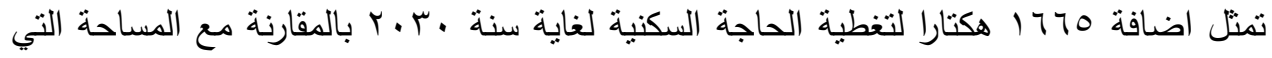
يشغلها السكن حاليا والذي يقدر بـ 90 هكتارا اضافة قدرها و ا \% لواقع الحال السكني، كما انها تشكل حوالي ^ץ\% من مساحة مدينة النصر والسلام حاليا والتي تبلغ مبـء هكتارا. جدول (v)

مساحات الأراضي المطلوبة للاسكان في مدينة النصر والسلام لغاية سنة الهدف .r.r.

\begin{tabular}{|c|c|}
\hline 38,727 & عدد الوحدات السكنية المطلوب تثييدها لغاية سنة الهـف \\
\hline 10,972 & عدد الوحدات السكنية غير المشيدة حاليا والتي توجد اراضيها ضمن الافرازات السكنية حاليا \\
\hline 27,756 & عدد الوحدات السكنية التي يجب توفير اراضي لها لغاية سنة 2030 \\
\hline 8 & معدل عدد أَفراد الأسرة في مدينة النصر والسلام \\
\hline 50 & المساحة الإسكانية المخصصة لكل فرد (م2) \\
\hline 1,110 & مساحة الأراضي السكنية المطلوب توفيرها مبئيًا (هكتار) \\
\hline 333 & حركة 30\% \\
\hline 222 & مراكز محلات واحتياط 20\% \\
\hline 1,665 & المساحة الإسكانية المطلوية النهائية لغاية سنة 2030 \\
\hline
\end{tabular}

المصدر : جهد الباحثة بالاعتماد على وزارة البلديات والاشغال العامة/ المديرية العامة للتخطيط العمراني/ قسم التخطيط/

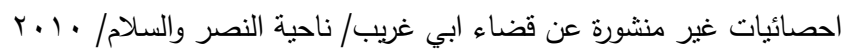




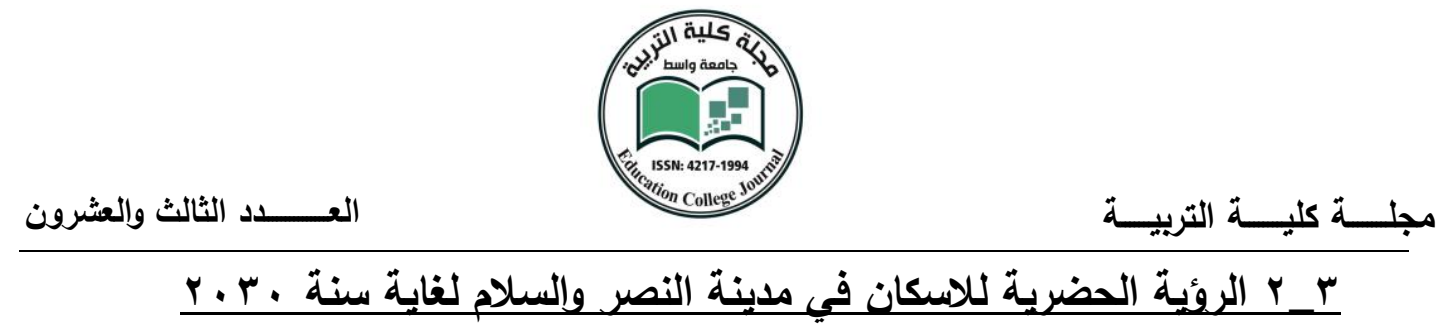

من الاعتبارات التي ينبغي الاخذ بها عند النظر إلى مستقبل المدينة لغرض تحسين صورة

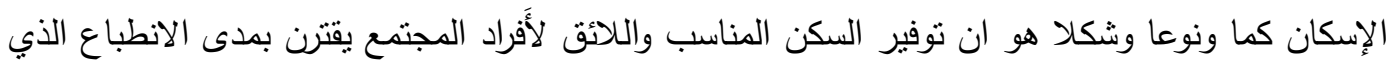

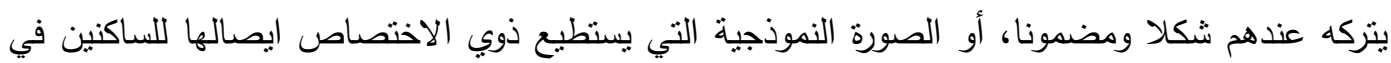
المدينة، وهذا الجانب قد اخذ الحيز الاكبر من مفهوم الدراسات التخطيطية الحديثة (10).

تحتاج الافرازات السكنية في مدينة النصر والسلام مستقبلا إلى الاهتمام بالجوانب العمرانية والثنكل الحضري للاسكان، من حيث انساق الواجهات وتوفر المناطق الخضراء وساحات اللعب والخدمات الفنية والاجتماعية ومسالك الحركة للمشاة، وبالثكل الذي يجعل البيئة المحيطة بالساكنين ملائمة تخطيطيا وصحيا.

\section{الاستتتاجسات والتوصيات}

\section{الاستنتاجات وإلتوصيات العامة}

1- الكثافة الإسكانية مقدرة بـ (وحدةا هكتار) أو (اسرةا هكتار) تساعد في تحديد صورة نمط الإسكان المطلوب توفيره في المنطقة الحضرية وذلك لارتباطها بعدد السكان والمساحة المطلوب اسكانهم فيها.

ץ- يؤثر حجم الأسرة في الكثافة الإسكانية فكلما كان حجم الأسرة كبيرا انخفضت كثافة الوحدات السكنية، بالمقابل تزداد كثافة السكان (فردا هكتار ) بالمنطقة.

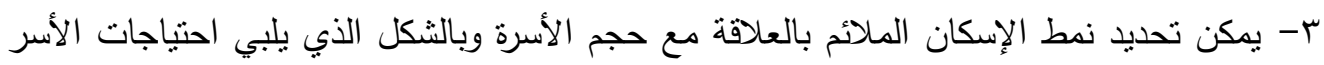
الصغيرة والمتوسطة والكبيرة وضمن الكثافات المقبولة تخطيطيا.

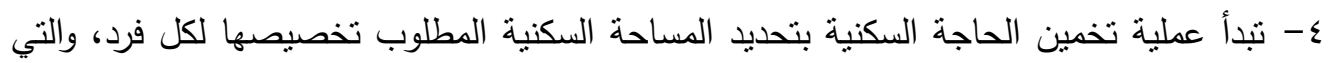

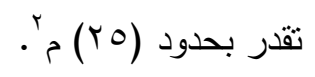

0- هناك حاجة للساحة اضافية لتغطية استخدامات الفضاءات الخارجية والحركة والحدائق ومواقف

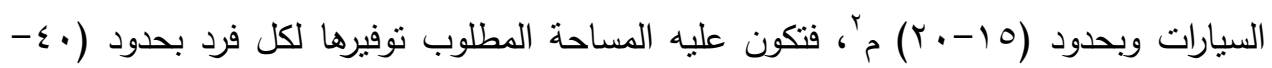
$\therefore$ r 
1- يمكن التوصل إلى المساحة الأولية للمنطقة بالعلاقة مع عدد السكان المطلوب نوفير المساحة

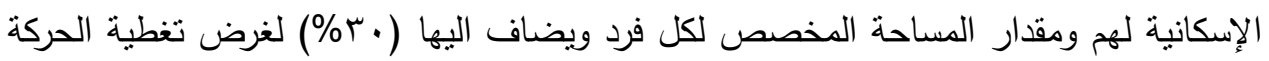

والثوارع.

V- تضاف نسبة (·r\%) لتغطية مساحة مراكز الدحلات (الفعاليات التعليمية والتجارية وغيرها).

\section{الأستنتاجات والتوصيات الخاصة بمنطقة الاراسة:}

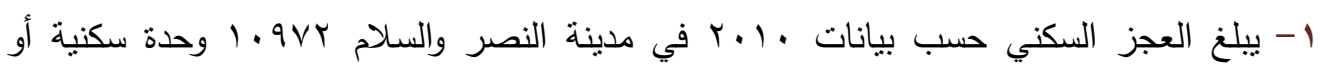

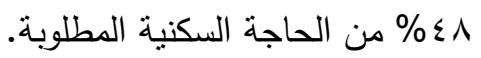

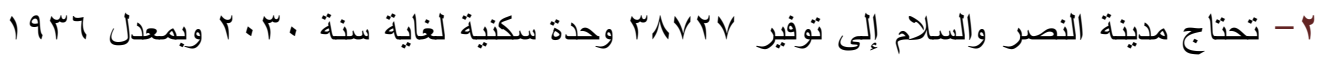
وحدة سكنية سنويا، وبمساحة اضافية تقدر بـ 1770 هكتارا.

r- توفر المدينة حاليا قابلية استيعاب العجز السكني لسنة ـ ـ ـ اذ ان سبب العجز هو عدم تشيبد

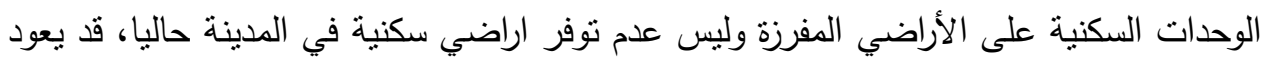

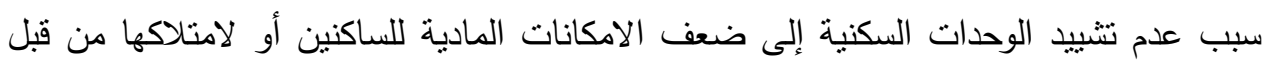
أَفراد لا يسكنون المدينة حاليا أو بسبب تغير اسعار الأراضي بفعل المضلاربات العبات العقارية. ع- يمكن القول ان مدينة النصر والسلام قد وصلت إلى طاقتها الاستيعابية القصوى ضمن الافرازات

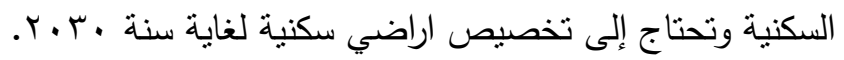
ه- ينبغي التركيز على السكن العمودي بوصفه احد بدائل نوفير السكن بسعر مناسب وضئ وضمن متتاول الغالبية.

4- تحتاج الافرازات السكنية الحالية إلى اعادة تأهيل من حيث الخدمات والبنى التحتية.

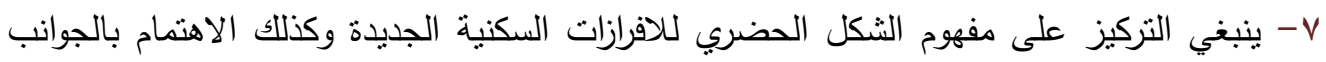

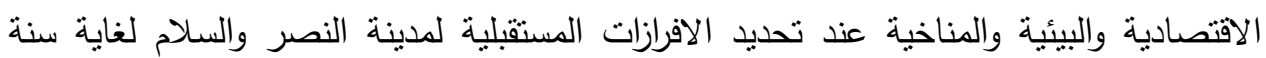


لاتقتصر تخمينات الحاجة السكنية على تحديد عدد الوحدات السكنية المطلوب نوفيرها وهناك

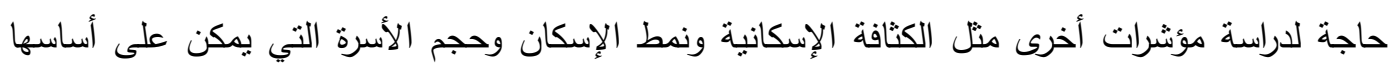

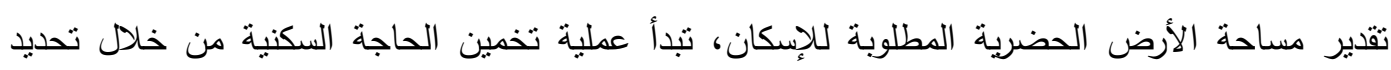
المساحة المطلوبة لكل فرد وبالعلاقة مع عدد السكان وتضاف اليها مساحات الثوارع ومراكز المحلات.

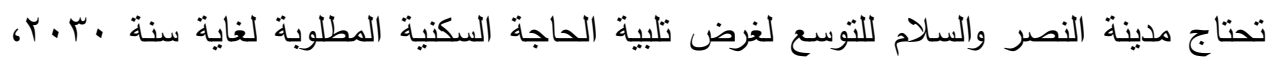

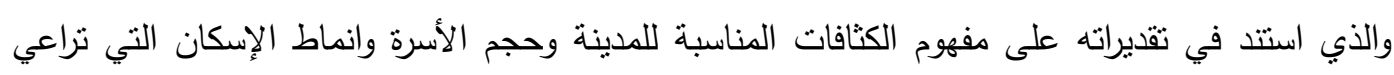
الجوانب الاقتصادية والاجتماعية والبيئية، ومن خلال معيار المساحة لكل شخص والذي توصلت اليه اليه الباحثة من واقع مدينة النصر والسلام. 
1- المصدر : الباحثة بالاستتاد إلى: الهيئة العامة للاسكان، "كراس معايير الإسكان الحضري"، وزارة

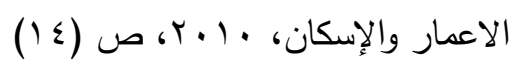

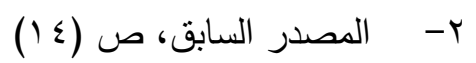

Pacione, Michael, "Urban Geography-a Global Perspective", $3^{\text {rd }}$ Edition, $\quad-r$ Routledge, 2 Park Square, Milton Park, Abingdon, Oxon OX14 4RN,

$$
\begin{aligned}
& \text { 2009, p517 }
\end{aligned}
$$

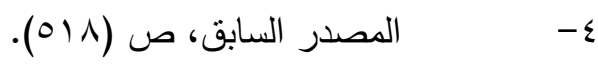

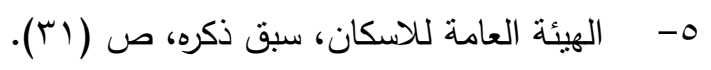

$$
\begin{aligned}
& \text { ד- المصدر السابق، ص (rr). } \\
& \text { - - المصدر السابق، ص (Tr) }
\end{aligned}
$$

1- وزارة البلديات والاثغال العامة/ مديرية التخطيط العمراني/ قسم التخطيط/ احصائيات غير منشورة

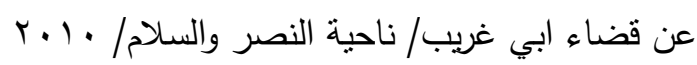

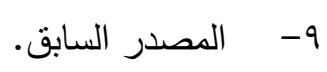

• 1- وفقا لخطة وزارة البلديات والاشغال العامة ومحافظة بغداد ضمن مشاريع تتمية الاقاليم لتطوير قضاء ابي غريب وناحية النصر والسلام.

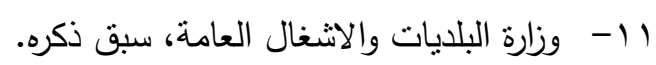

$$
\begin{aligned}
& \text { rا - المصدر السابق. } \\
& \text { ז זا- المصدر السابق. } \\
& \text { ع ا- - المصدر السابق. }
\end{aligned}
$$

Colquhoun, Ian, "RIBA Book of British Housing", 2nd ed., Architectural -10 Press, Oxford, 2008, p14 